\title{
Optimal Selection of Different Control Input Signals to UPFC Damping Controller for Stabilization of Low- Frequency Oscillations
}

\author{
Mohammed Osman Hassan ${ }^{1}$ and Ahmed Khaled Al-haj ${ }^{2}$ \\ ${ }^{1}$ Sudan University of Science and Technology, Electrical and Nuclear School, Sudan. \\ ${ }^{2}$ Khartoum University, Electrical and Electronics Department, Sudan.
}

\begin{abstract}
:
Assessment the performance of Unified Power Flow Controller (UPFC) based on the stabilizing controllers for damping LowFrequency Oscillations (LFO) has been conducted on Single Machine Infinite Bus (SMIB) power system in this paper. A detailed investigation has been carried out considering different modulating signals as input signals for stabilizing controllers. Particle Swarm Optimization (PSO) has been chosen as the optimization algorithm for computing the optimal parameters of the proposed stabilizing controllers. Eigenvalues and simulation results have been adopted for assessment and analysis of the performance, effectiveness and robustness of the proposed design approach.
\end{abstract}

Keywords: Single Machine Infinite Bus (SMIB), Power System Stabilizer (PSS), Unified Power Flow Controller (UPFC), Particle Swarm Optimization (PSO).

\section{INTRODUCTION}

Flexible ac Transmission System (FACTS) considered one of emerging technologies which helped in efficient operation and optimal management of power systems in last years. This technology has high potential of flexibility and reliability, that capable of secure and economic operation of power system. In general, FACTS devices can be employed to increase the transmission line capacity, improve the stability margin and enhancement the power quality. These features can be executed through control of voltage, power flow and reactive power compensation. Various kinds of FACTS devices are such as Static Var Compensator (SVC), Thyristor Controlled Series Compensator (TCSC), Static Synchronous Series Compensator (SSSC), Static Compensator (STATCOM) and Unified Power Flow Controller (UPFC). Among the FACTS family, UPFC consider a multifunction device that can be simultaneously control of voltage magnitude of and phase angle of installed bus in addition to transmission line power flow voltage and angle for optimal operation performance of power systems. [1-3]

Power System Stabilizer (PSS) was one of early successful solutions that have been widely assigned to improve the power system stability through damp out the power system oscillations. Simplicity of structure, easy on-line tuning of parameters and effectiveness in damping the oscillations made it the preferred solution in that time in addition to economical cost. [4,5] On another hand, with utilizing the UPFC for power flow control also can be employed for enhancement the dynamic performance of power system stability. Determining the UPFC stabilizing controller parameters is a difficult issue. So, heuristic algorithms such as Genetic algorithm (GA), Particle Swarm Optimization (PSO) and Simulated Annealing (SA) are appeared on surface in recent years and used for search about the optimal solution of under taken stabilizing controller. PSO has been assigned in this work for tuning the optimal parameters of UPFC damping controller based on different control signals. Controllability and observability concepts have been used to define the best control signal. This proposed stabilizing controller is tested on a SMIB power system when subjected to sudden short circuit. Verification the system performance was through eigenvalues and time domain simulation of power system. [6,7]

\section{POWER SYSTEM MODELLING}

Figure (1) shows the SMIB power system installed with UPFC. The UPFC composed of two Voltage Source Converters (VSC) linked together by DC capacitor that help in smoothly transferring of real power between two VSC's. The two VSC's connected in parallel and in series with transmission line through Excited Transformer (ET) and Boost Transformer (BT). 


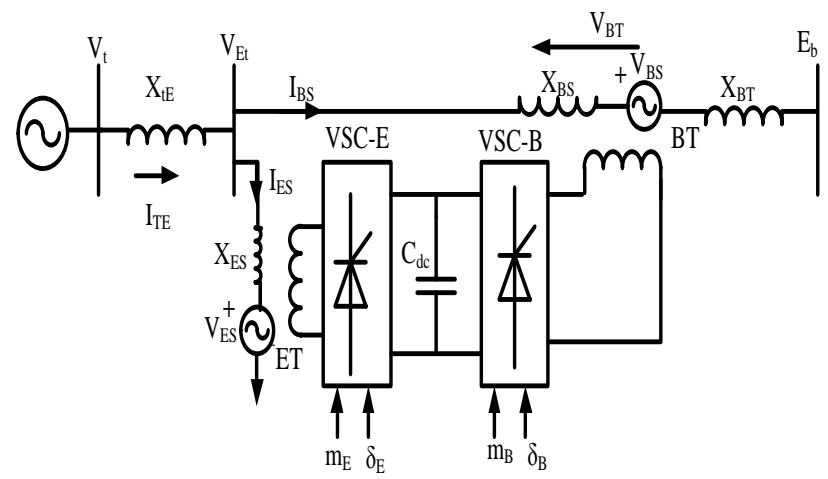

Figure 1: SMIB power system with UPFC.

The dynamic performance of SMIB power system equipped with UPFC can be assessed through nonlinear equations that describe the system as mentioned bellow:

$$
\begin{aligned}
& \dot{\delta}=\omega_{0}(\omega-1) \\
& \dot{\omega}=\frac{\mathrm{P}_{\mathrm{m}}-\mathrm{P}_{\mathrm{e}}-\mathrm{P}_{\mathrm{D}}}{\mathrm{M}} \\
& \dot{\mathrm{E}}_{\mathrm{q}}=\frac{\left(-\mathrm{E}_{\mathrm{q}}+\mathrm{E}_{\mathrm{fd}}\right)}{\mathrm{T}_{\mathrm{d} 0}^{\prime}} \\
& \dot{\mathrm{E}}_{\mathrm{fd}}=\frac{-\mathrm{E}_{\mathrm{fd}}+\mathrm{K}_{\mathrm{A}}\left(\mathrm{V}_{\mathrm{ref}}-\mathrm{V}_{\mathrm{t}}\right)}{\mathrm{T}_{\mathrm{a}}} \\
& \dot{\mathrm{V}}_{\mathrm{dc}}=\frac{\mathrm{m}_{\mathrm{e}} \mathrm{k}_{\mathrm{e}}}{\mathrm{C}_{\mathrm{dc}}}\left[\begin{array}{ll}
\cos \psi_{\mathrm{e}} & \sin \psi_{\mathrm{e}}
\end{array}\right]\left[\begin{array}{l}
\mathrm{i}_{\text {esd }} \\
\mathrm{i}_{\mathrm{esq}}
\end{array}\right]+\quad \frac{\mathrm{m}_{\mathrm{b}} \mathrm{k}_{\mathrm{b}}}{\mathrm{C}_{\mathrm{dc}}}\left[\begin{array}{cc}
\cos \psi_{\mathrm{b}} & \sin \psi_{\mathrm{b}}
\end{array}\right]\left[\begin{array}{l}
\mathrm{i}_{\mathrm{bsd}} \\
\mathrm{i}_{\mathrm{bsq}}
\end{array}\right]
\end{aligned}
$$

Where:

$$
\begin{aligned}
& \mathrm{P}_{\mathrm{e}}=\mathrm{V}_{\mathrm{td}} \mathrm{I}_{\text {ted }}+\mathrm{V}_{\mathrm{tq}} \mathrm{I}_{\text {teq }} \\
& \mathrm{E}_{\mathrm{q}}=\mathrm{E}_{\mathrm{q}}+\left(\mathrm{x}_{\mathrm{d}}-\dot{\mathrm{x}}_{\mathrm{d}}\right) \mathrm{i}_{\text {ted }} \\
& V_{t}=V_{t d}+j V_{t q} \\
& \mathrm{~V}_{\mathrm{td}}=\mathrm{x}_{\mathrm{q}}\left(\mathrm{I}_{\mathrm{esq}}+\mathrm{I}_{\mathrm{bsq}}\right) \\
& \mathrm{V}_{\mathrm{tq}}=\hat{\mathrm{E}}_{\mathrm{q}}-\dot{\mathrm{x}}_{\mathrm{d}}\left(\mathrm{I}_{\mathrm{esd}}+\mathrm{I}_{\mathrm{bsd}}\right) \\
& \overline{\mathrm{I}_{\mathrm{te}}}=\overline{\mathrm{I}_{\mathrm{es}}}+\overline{\mathrm{I}_{\mathrm{bs}}} \\
& I_{\text {ted }}=I_{\text {esd }}+I_{\text {bsd }} \\
& I_{\text {teq }}=I_{\text {esq }}+I_{\text {bsq }} \\
& {\left[\begin{array}{c}
\mathrm{V}_{\mathrm{Etd}} \\
\mathrm{V}_{\mathrm{Etq}}
\end{array}\right]=\left[\begin{array}{cc}
0 & -\mathrm{X}_{\mathrm{es}} \\
\mathrm{X}_{\mathrm{es}} & 0
\end{array}\right]\left[\begin{array}{c}
\mathrm{I}_{\mathrm{Esd}} \\
\mathrm{I}_{\mathrm{Esq}}
\end{array}\right]+\left[\begin{array}{c}
\mathrm{m}_{\mathrm{e}} \mathrm{k}_{\mathrm{e}} \mathrm{V}_{\mathrm{dc}} \cos \psi_{\mathrm{es}} \\
\mathrm{m}_{\mathrm{e}} \mathrm{k}_{\mathrm{e}} \mathrm{V}_{\mathrm{dc}} \sin \psi_{\mathrm{es}}
\end{array}\right]} \\
& {\left[\begin{array}{c}
\mathrm{V}_{\mathrm{Btd}} \\
\mathrm{V}_{\mathrm{Btq}}
\end{array}\right]=\left[\begin{array}{cc}
0 & -\mathrm{X}_{\mathrm{bs}} \\
\mathrm{X}_{\mathrm{bs}} & 0
\end{array}\right]\left[\begin{array}{c}
\mathrm{I}_{\mathrm{Bsd}} \\
\mathrm{I}_{\mathrm{Bsq}}
\end{array}\right]+\left[\begin{array}{c}
\mathrm{m}_{\mathrm{b}} \mathrm{k}_{\mathrm{b}} \mathrm{V}_{\mathrm{dc}} \cos \psi_{\mathrm{bs}} \\
\mathrm{m}_{\mathrm{b}} \mathrm{k}_{\mathrm{b}} \mathrm{V}_{\mathrm{dc}} \sin \psi_{\mathrm{bs}}
\end{array}\right]}
\end{aligned}
$$

Where $P_{m}$ and $P_{e}$ are input and output power respectively; $V_{r e f}$ and $V_{t}$ are reference and terminal voltage respectively. $m_{e}$ and $m_{b}$ are modulation index of shunt and series VSC respectively; $\psi_{e s}$ and $\psi_{b s}$ are phase angle of shunt and series VSC respectively. In state-space representation, the power system linear model can be modeled as:

$$
[\dot{\mathrm{X}}]=[\mathrm{A}][\mathrm{X}]+[\mathrm{B}][\mathrm{U}]
$$

Where:

The state vector and control vector matrices are:

$$
[\mathrm{X}]=\left[\begin{array}{lllll}
\Delta \hat{\mathrm{E}}_{\mathrm{q}} & \Delta \delta & \Delta \omega & \Delta \mathrm{E}_{\mathrm{fd}} & \mathrm{V}_{\mathrm{dc}}
\end{array}\right]^{\mathrm{T}}
$$


$[\mathrm{U}]=\left[\begin{array}{lllll}\Delta \mathrm{u}_{\mathrm{PSS}} & \Delta \mathrm{m}_{\mathrm{E}} & \Delta \delta_{\mathrm{E}} & \Delta \mathrm{m}_{\mathrm{B}} & \Delta \delta_{\mathrm{B}}\end{array}\right]^{\mathrm{T}}$

$$
\mathrm{A}=\left[\begin{array}{ccccc}
0 & \omega_{0} & 0 & 0 & 0 \\
-\frac{\mathrm{K}_{1}}{\mathrm{M}} & -\frac{\mathrm{D}}{\mathrm{M}} & -\frac{\mathrm{K}_{2}}{\mathrm{M}} & 0 & -\frac{\mathrm{K}_{\mathrm{Pdc}}}{\mathrm{M}} \\
-\frac{\mathrm{K}_{4}}{\grave{\mathrm{T}}_{\mathrm{do}}} & 0 & -\frac{\mathrm{K}_{3}}{\grave{\mathrm{T}}_{\mathrm{do}}} & \frac{1}{\grave{\mathrm{T}}_{\mathrm{do}}} & -\frac{\mathrm{K}_{\mathrm{qdc}}}{\grave{\mathrm{T}}_{\mathrm{do}}} \\
-\frac{\mathrm{K}_{\mathrm{A}} \mathrm{K}_{5}}{\mathrm{~T}_{\mathrm{A}}} & 0 & -\frac{\mathrm{K}_{\mathrm{A}} \mathrm{K}_{6}}{\mathrm{~T}_{\mathrm{A}}} & -\frac{1}{\mathrm{~T}_{\mathrm{A}}} & -\frac{\mathrm{K}_{\mathrm{A}} \mathrm{K}_{\mathrm{Vdc}}}{\mathrm{T}_{\mathrm{A}}} \\
\mathrm{K}_{7} & 0 & \mathrm{~K}_{8} & 0 & -\mathrm{K}_{9}
\end{array}\right] ;
$$

0
$-\frac{\mathrm{K}_{\mathrm{P} \delta \mathrm{e}}}{\mathrm{M}}$
$-\frac{\mathrm{K}_{\mathrm{q} \delta \mathrm{e}}}{\mathrm{T}_{\mathrm{do}}}$
$-\frac{\mathrm{K}_{\mathrm{A}} \mathrm{K}_{\mathrm{V} \delta \mathrm{e}}}{\mathrm{T}_{\mathrm{A}}}$
$\mathrm{K}_{\mathrm{d} \delta \mathrm{e}}$

$$
\left.\begin{array}{c}
0 \\
-\frac{\mathrm{K}_{\mathrm{P} \delta \mathrm{b}}}{\mathrm{M}} \\
-\frac{\mathrm{K}_{\mathrm{q} \delta \mathrm{b}}}{\dot{\mathrm{T}}_{\mathrm{do}}} \\
-\frac{\mathrm{K}_{\mathrm{A}} \mathrm{K}_{\mathrm{V} \delta \mathrm{b}}}{\mathrm{T}_{\mathrm{A}}} \\
\mathrm{K}_{\mathrm{d} \delta \mathrm{e}}
\end{array}\right]
$$

\section{STABILIZING CONTROLLERS}

The main function of stabilizing controllers is producing electrical torque in-phase with speed deviation. So, PSS is one these controllers which constructed of gain block, washout filter block and two stages of lead-lag blocks as shown in figure (2). The transfer function of PSS is:

$$
\mathrm{u}_{\mathrm{PSS}}=\mathrm{K} \frac{\mathrm{sT}_{\mathrm{W}}}{1+\mathrm{sT}_{\mathrm{W}}}\left[\frac{1+\mathrm{sT}_{1}}{1+\mathrm{sT}_{2}}\right]\left[\frac{1+\mathrm{sT}_{3}}{1+\mathrm{sT}_{4}}\right] \Delta \omega
$$

The structure of UPFC stabilizing controllers is shown in figure (3), where the controlled signal $u$ can be $m_{e}, m_{b}, \delta_{e}$ or $\delta_{b}$. Maintain the power balance between the shunt and series converters depend on the DC link between them. This link controlled by PI controller.

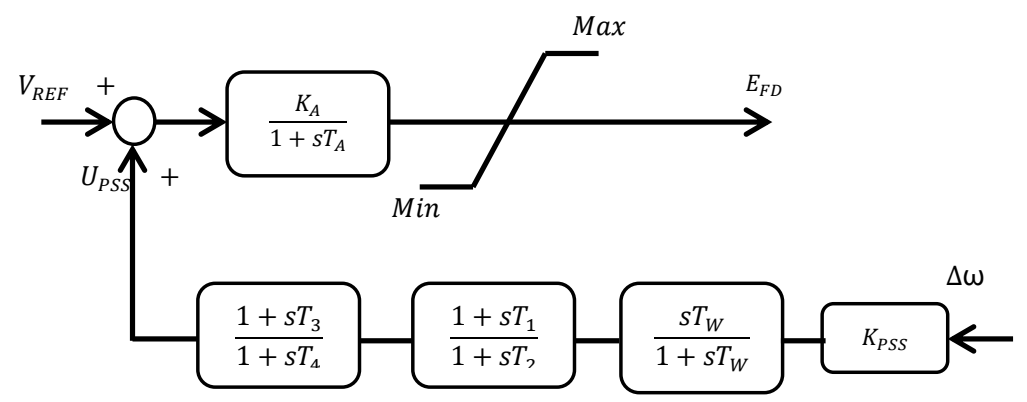

Figure 2: PSS structure.

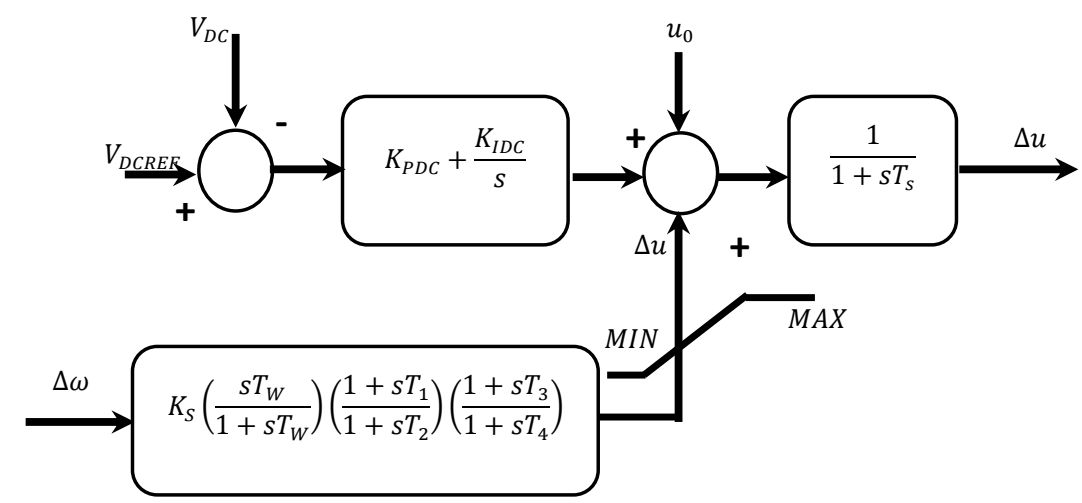

Figure 3: UPFC stabilizing and PI controllers.

\section{OPTIMIZATION PROBLEM}

\subsection{Controllability Measure}

Controllability concept is employed to define the best signals associated with Electromechanical Mode (EM) that can be used as input signals of stabilizing controllers. The input vector matrix can be expressed by $B=\left[b_{1} b_{2} b_{3} b_{4} b_{5}\right]$ corresponding to $i$-th input of controlled signals. Equation (19) represents the mathematical expression of controllability concept. Actually, the candidate signal that has a higher index associated with EM. 
Where: $\Phi, \mathrm{B}$ are right eigenvectors and input matrix of system.

\subsection{Objective Function}

To determine the optimal parameters of stabilizing controllers that improve the power system stability, two kinds of objective functions have been assigned to optimize. This objective functions has one aim is decrease the required time for settling the system. The first objective function $\left(f_{l}\right)$ is eigenvalue-based that given by:

$$
\mathrm{f}_{1}=\operatorname{Max}\left(-\sigma / \sqrt{\sigma^{2}+\omega^{2}}\right)
$$

It's aimed to improve the dynamic performance of power system through maximize the damping ratio of EM of power system. While the second objective function $\left(f_{2}\right)$ is time-domain simulation based that can described by:

$$
\mathrm{f}_{2}=\operatorname{Min}\left(\int_{\mathrm{t}=0}^{\mathrm{t}_{\operatorname{sim}}}|\Delta \omega| \cdot \mathrm{t} \mathrm{dt}\right)
$$

It's aimed to minimize the power system oscillations through reduce the time-weighted speed deviation. Hence, optimize the objective functions $\left(\mathrm{f}_{1}\right.$ and $\mathrm{f}_{2}$ ) within unequal constraint of parameters is the problem of design that given by:

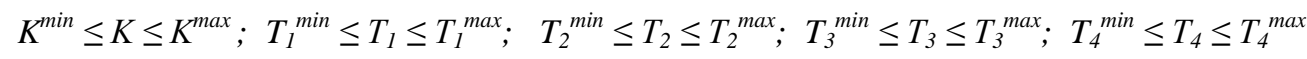

PSO algorithm has been employed for search about the optimal parameters of the proposed controllers, take into consideration two objective functions.

\subsection{Particle Swarm Optimization Technique}

The PSO is a new evolutionary algorithm for global search of optimized solutions. It's based on for food searching behavior. The PSO similar to other heuristic algorithms such as GA, SA, etc., begin with random members forms an initial population. The members of this population called particles $\left(P_{i}\right)$. The $i^{\text {th }}$ particle is represented by $X_{i}=\left(x_{i 1}, x_{i 2}, \ldots, x_{i n}\right)$. Each particle changes its velocity at each step towards to local best solution $\left(P_{\text {best }}\right)$ and then to global best solution $\left(g_{\text {best }}\right)$ following the equation given by:

$$
V_{i d}=w^{*} V_{i d}+c_{1} * r^{*}\left(p_{i d}-x_{i d}\right)+c_{2} * r *\left(p_{g d}-x_{i d}\right)
$$

Where; $\mathrm{r}$ and $\mathrm{c}_{1}, \mathrm{c}_{2}$ are random number and learning factors respectively. Position of $i^{\text {th }}$-particle is then updated as:

$$
X_{i d}=x_{i d}+v_{i d}
$$

The flow chart explains the detailed steps of PSO algorithm as shown in figure (4).

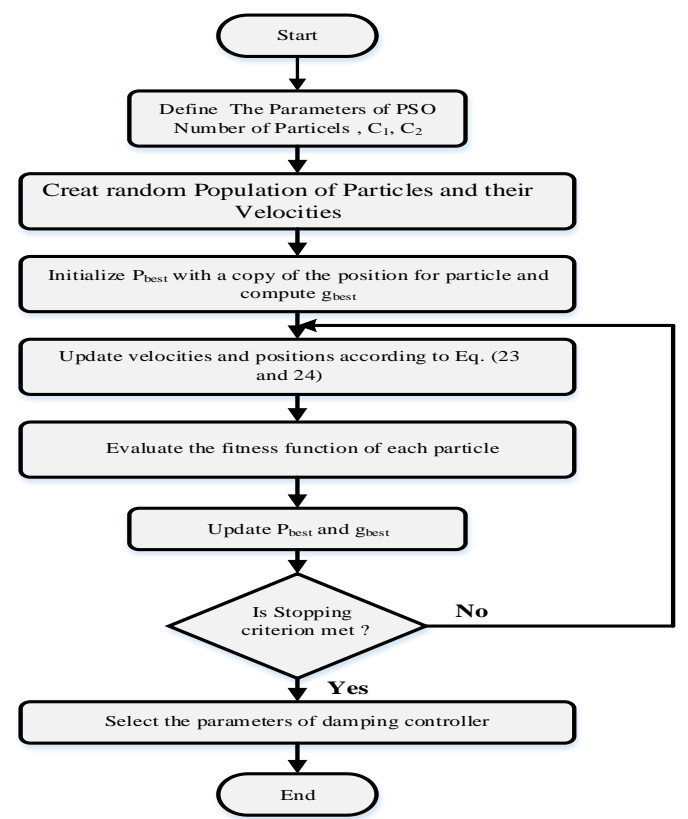

Figure 4: PSO flow chart. 


\section{SIMULATION RESULTS}

\subsection{Controllability Measure}

Controllability indices associated with EM mode is employed to define the candidate signals from each five controlled signals: $\mathrm{u}_{\mathrm{pss}}, \mathrm{m}_{\mathrm{E}}, \delta_{\mathrm{E}}, \mathrm{m}_{\mathrm{B}}$ and $\delta_{\mathrm{B}}$. The best signals that have higher indices as shown in table (1). It's clear, the best signals are $\delta_{E}$ and $m_{B}$ while the other signals are the worst signals.

Table 1: Controllability indices of input signals.

\begin{tabular}{|c|c|}
\hline Signal & Controllability Index \\
\hline$\Delta u_{P S S}$ & 0.5284 \\
\hline$\Delta m_{E}$ & 2.1113 \\
\hline$\Delta \delta_{E}$ & 19.7381 \\
\hline$\Delta m_{B}$ & 5.8158 \\
\hline$\Delta \delta_{B}$ & 0.2147 \\
\hline
\end{tabular}

\subsection{Stabilizer Design}

The stabilizing controller is designed to produce an electrical torque in-phase with the speed deviation. PSO algorithm has been employed in this paper to compute the optimal parameters settings of each controller based on two objective functions. It's important to mention, the PI controller parameters of DC voltage regulator have been assigned prior to the values shown in table (2). Moreover, the best parameters of the supplementary controllers and objective function values have been computed when the system was operate at normal condition as shown in figures $(5,6)$. It's worth noting that, the worst signals of UPFC stabilizing controller $\left(m_{E}\right.$ and $\left.\delta_{B}\right)$ have been excluded from the analysis and study.

Table (2): The optimal parameters of stabilizing controllers.

\begin{tabular}{|c|c|c|c|c|c|c|}
\hline & \multicolumn{2}{|c|}{ PSS } & \multicolumn{2}{c|}{$\delta_{\mathrm{E}}$} & \multicolumn{2}{c|}{$\mathbf{m}_{\mathrm{B}}$} \\
\hline & $\boldsymbol{f}_{\boldsymbol{l}}$ & $\boldsymbol{f}_{\boldsymbol{2}}$ & $\boldsymbol{f}_{\boldsymbol{l}}$ & $\boldsymbol{f}_{2}$ & $\boldsymbol{f}_{\boldsymbol{I}}$ & $\boldsymbol{f}_{\boldsymbol{2}}$ \\
\hline $\boldsymbol{K}$ & 11.64 & 9.692 & 3.0 & 20.83 & 8 & 40.52 \\
\hline $\boldsymbol{T}_{\boldsymbol{l}}$ & 1.0 & 1.5 & 0.1 & 0.1 & 1.0 & 1.5 \\
\hline $\boldsymbol{T}_{\boldsymbol{2}}$ & 0.1 & 0.1 & 0.125 & 0.68 & 0.514 & 1.5 \\
\hline $\boldsymbol{T}_{3}$ & 0.362 & 0.3491 & 1.0 & 1.5 & 1.0 & 1.5 \\
\hline $\boldsymbol{T}_{\boldsymbol{4}}$ & 0.1 & 0.1 & 0.2876 & 0.1 & 0.5135 & 0.9411 \\
\hline $\boldsymbol{f}$ & $\mathbf{0 . 5 2 9}$ & $\mathbf{0 . 1 6 6}$ & $\mathbf{0 . 7 4 1}$ & $\mathbf{9 . 6 e}^{-4}$ & $\mathbf{0 . 7 1 5}$ & $\mathbf{9 . 5}^{-4}$ \\
\hline
\end{tabular}

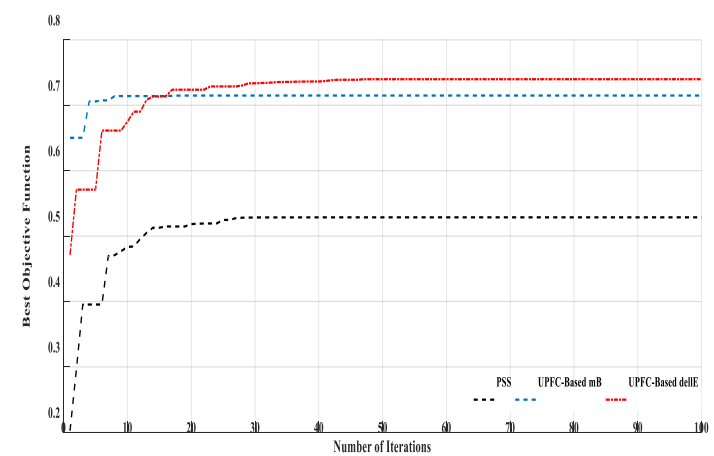

Figure 5: Optimal objective function graph based $\left(f_{1}\right)$. 


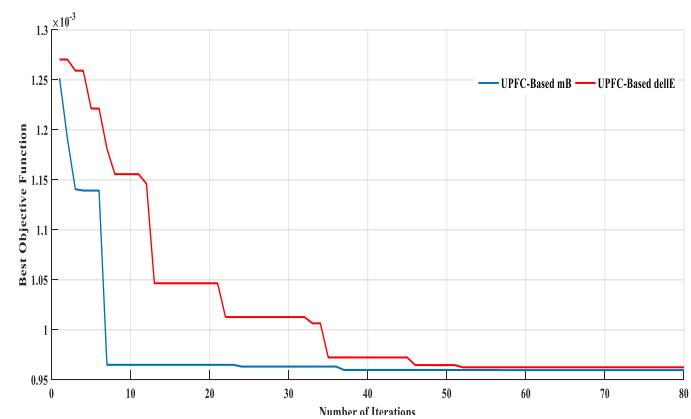

Figure 6: Optimal objective function graph based $\left(f_{2}\right)$.

\subsection{Eigenvalue Analysis and Time-Domain Simulation}

The major role of stabilizing controllers is improving the power system stability margins. So, the eigenvalues of system and time domain-simulations under three different operating conditions demonstrates its performance.

\subsubsection{Eigenvalues Analysis}

The eigenvalues of system and their damping ratio that have marked by bold line refers to an EM mode as detailed in table (3). It's obvious that, the system without any stabilizing controller under three loading conditions: normal, heavy and light is poorly damped. While when the stabilizing controllers have included, the system performance greatly improved in damping the low frequency oscillations. From this table, it can be concluded that:

Table (3): System eigenvalues and damping ratios with and without control at different loading conditions.

\begin{tabular}{|c|c|c|c|c|c|c|}
\hline & \multicolumn{2}{|c|}{ Normal Load } & \multicolumn{2}{|c|}{ Heavy Load } & \multicolumn{2}{|c|}{ Light Load } \\
\hline & Eigenvalues & D. Ratio & Eigenvalues & D. Ratio & Eigenvalues & D. Ratio \\
\hline$W . C$ & $\begin{array}{c}\mathbf{- 0 . 0 0 4 9} \pm \mathbf{j 8 . 1 0 8 0} \\
-99.2852 ;-1.1720 \\
-0.0141\end{array}$ & 0.0006 & $\begin{array}{c}\mathbf{- 0 . 0 0 1 0} \pm \mathbf{j 8 . 7 6 1 6} \\
-99.2791 ;-1.1881 \\
-0.0169\end{array}$ & 0.0001 & $\begin{array}{c}\mathbf{- 0 . 0 0 7 5} \pm \mathbf{j} 7.1660 \\
-99.2663 ;-1.1967 \\
-0.0064\end{array}$ & 0.001 \\
\hline PSS & $\begin{array}{l}-4.7073 \pm j 7.6240 \\
-4.7679 \pm j 7.5899 \\
-100.34 ;-1.1783 \\
-0.1003 ;-0.0141\end{array}$ & 0.5254 & $\begin{array}{c}\mathbf{- 3 . 4 2 2 8} \pm \mathbf{j 9 . 4 1 7 3} \\
-6.0655 \pm \mathrm{j} 6.1957 \\
-1.1939 ;-100.30 \\
-0.1003 ;-0.0169\end{array}$ & 0.3417 & $\begin{array}{l}\mathbf{- 1 . 8 7 9 2} \pm \mathbf{j 6 . 9 0 5 6} \\
-7.7695 \pm \text { j6.1977; } \\
-99.9774 ;-1.2029 \\
-0.1003 ;-0.0064\end{array}$ & 0.2626 \\
\hline$U P F C-\delta_{E}$ & $\begin{array}{c}\mathbf{- 5 . 5 2 5 3} \pm \mathbf{j 5 . 0 1 3 6} \\
-4.2241 \pm \mathrm{j} 3.8475 \\
-1.1729 ;-0.1004 \\
-0.0141\end{array}$ & 0.7406 & $\begin{array}{c}-\mathbf{7 . 2 4 8 5} \pm \mathbf{j 6 . 0 4 4 7} \\
-3.5612 \pm \mathrm{j} 3.3403 \\
-99.2797 ;-1.1891 \\
-0.1003 ;-0.0169\end{array}$ & 0.7680 & $\begin{array}{l}\mathbf{- 2 . 8 7 0 6} \pm \mathbf{j 5 . 3 8 4 6} \\
-5.6616 \pm \mathrm{j} 2.4599 \\
-99.2661 ;-1.1975 \\
-0.1005 ;-0.0064\end{array}$ & 0.4704 \\
\hline$U P F C-m_{B}$ & $\begin{array}{c}\mathbf{- 3 . 6 4 8 7} \pm \mathbf{j 5 . 3 6 9 9} \\
-99.2917 ;-3.5734 \\
-1.6502 ;-0.1003 \\
-0.0141 ;-1.1717\end{array}$ & 0.5620 & $\begin{array}{c}\mathbf{- 3 . 9 7 4 4} \pm \mathbf{j 6 . 1 2 6 3} \\
-99.2876 ;-1.6636 \\
-1.1877 ;-0.1003 \\
-0.0169\end{array}$ & 0.5442 & $\begin{array}{c}\mathbf{- 2 . 9 2 6 1} \pm \mathbf{j 4 . 7 6 2 1} \\
-99.2675 ;-3.7936 \\
-1.6377 ;-1.1967 \\
-0.1003 ;-0.0064\end{array}$ & 0.5253 \\
\hline
\end{tabular}

- The performance of the system when applied the UPFC based- $\delta_{\mathrm{E}}$ is considered the best $(0.741)$ at normal load comparing with the other stabilizing controllers.

- At heavy loading condition, the performance of UPFC based- $\delta_{\mathrm{E}}$ is considered the best $(0.768)$ comparing with the other stabilizers.

- At light loading condition, the performance of UPFC based- $\mathrm{m}_{\mathrm{B}}$ is considered the best $(0.525)$ comparing with the other stabilizers.

Of all have mentioned, ensures the performance of UPFC based- ( $\delta_{\mathrm{E}}$ and $\mathrm{m}$ ) characterized by robustness and effectiveness compared with PSS.

\subsubsection{Time Domain-Simulation}


The nonlinear time-domain simulations are carried out to verify the effectiveness and robustness of the optimized controllers. These controllers have been tuned based on different objective functions $\left(f_{l}\right.$ and $\left.f_{2}\right)$, and tested when the system subjected to three phase fault at bus (1), at $\mathrm{t}=1.0 \mathrm{sec}$. Rotor angle, speed deviation and electrical power have been chosen as system responses, and it's concluded to following:

- Figures (7-9), shows rotor angle and rotor speed when the system operates at normal loading condition, without, with the optimized controllers based $f_{1}$ and optimized controllers based $f_{2}$. It's obvious, great enhancement appeared on the system response when employed damping controller based- $\delta_{E}$ with comparing with the other damping controllers. The system response is a little better when using $f_{2}$ as objective function for tuning the stabilizing controller based- $\delta_{E}$, but the design cost is not little.

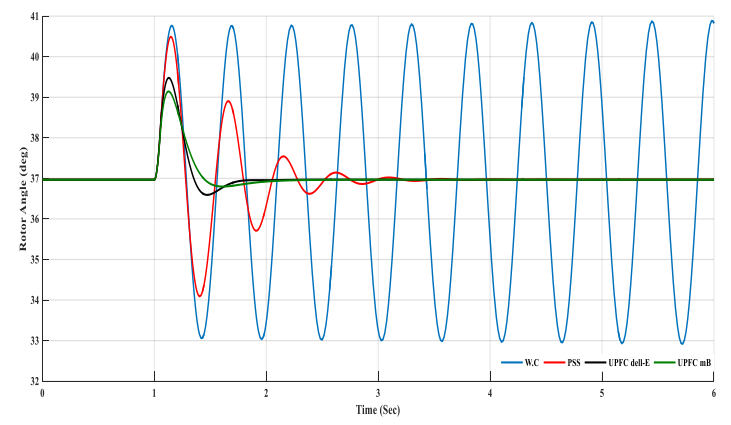

Figure 7: Rotor angle at normal load based $f_{1}$.

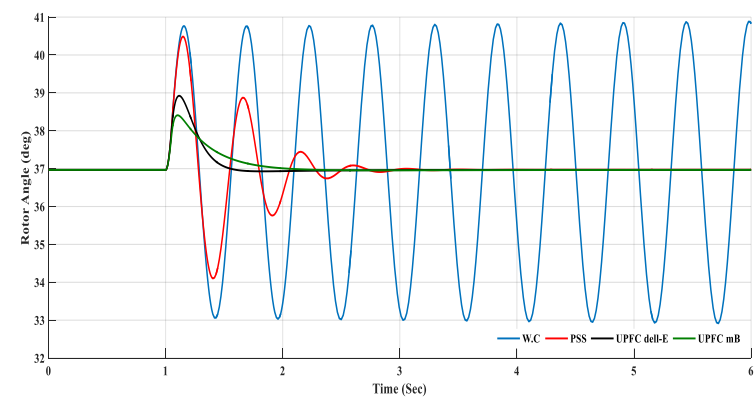

Figure 8: Rotor angle at normal load based $f_{2}$.

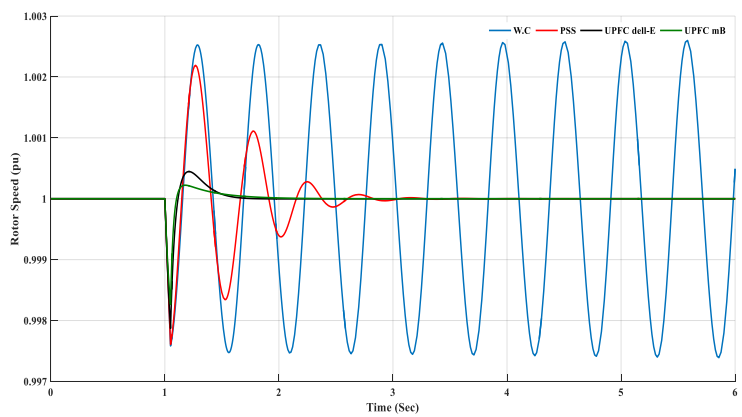

Figure 9: Rotor speed at normal load based $f_{l}$.

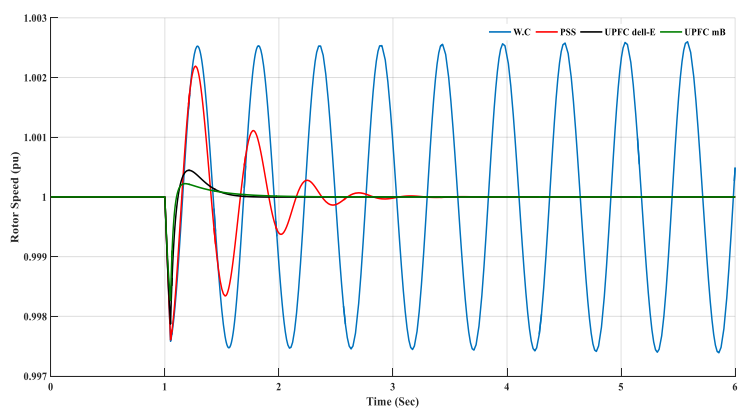

Figure 10: Rotor speed at normal load based $f_{2}$. 
- Also, under heavy load the system is oscillating. Figures (11-14) shows the rotor angle and speed deviation respectively. Once the optimized controller has applied, the performance of system greatly enhanced. It is obvious; the system performance when using the stabilizing controller based $-\delta_{\mathrm{E}}$ is considered the best versus the other signals.

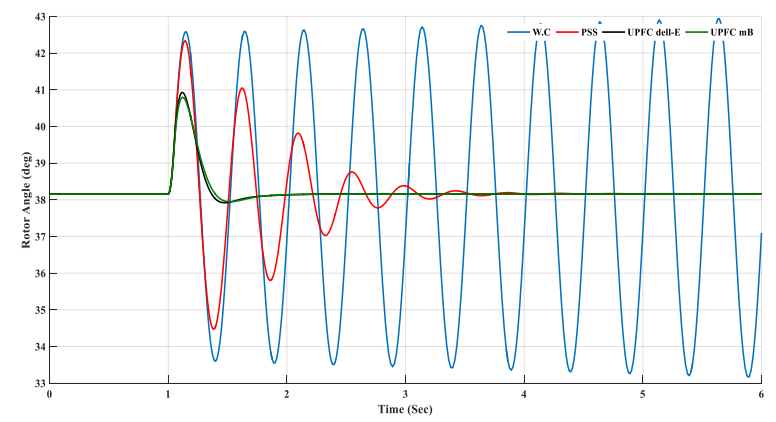

Figure 11: Rotor angle at heavy load based $f_{1}$.

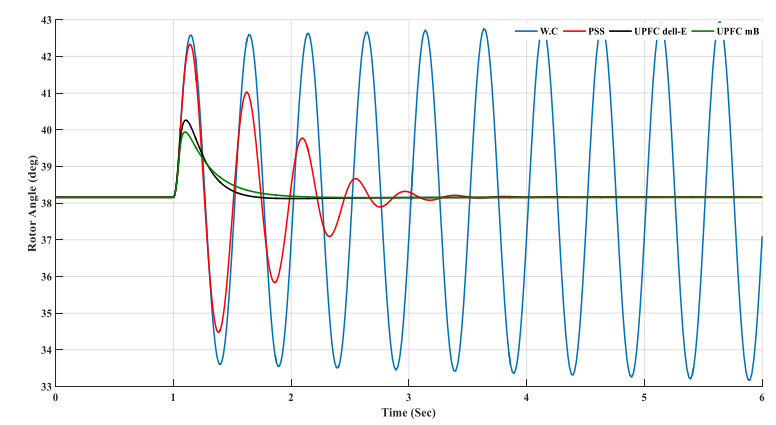

Figure 12: Rotor angle at heavy load based $f_{2}$.

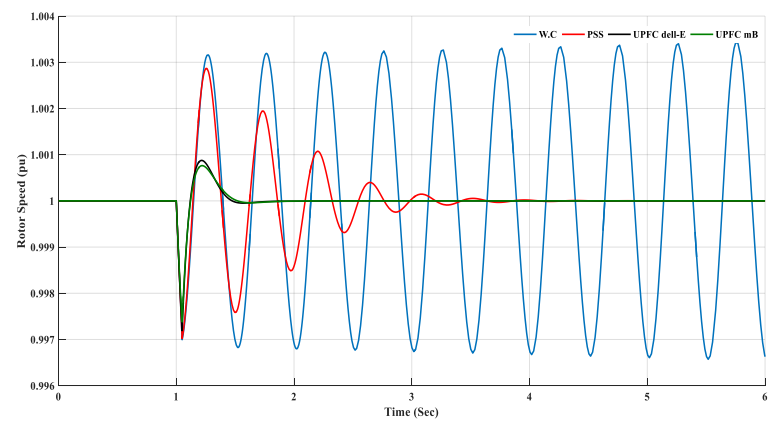

Figure 13: Rotor speed at heavy load based $f_{l}$.

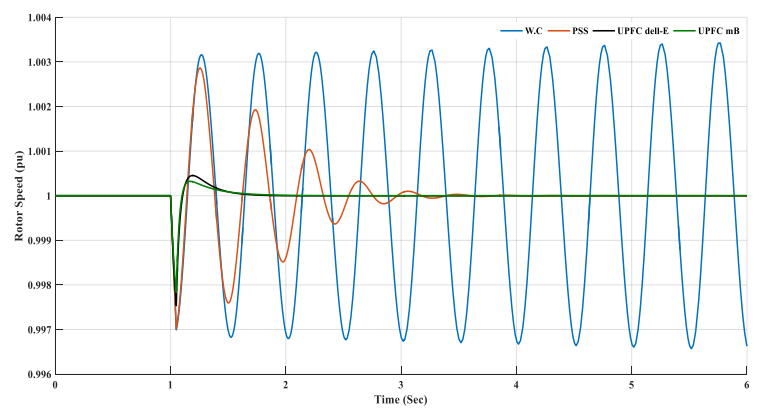

Figure 14: Rotor speed at heavy load based $f_{2}$. 
- At light load, the system became poorly damped. Rotor angle and speed deviation of stabilizing controllers based on two objective functions shown in figures (15-18) respectively. It's worth mentioning, the stabilizing controller based- $m_{B}$ made the system performance greatly enhanced versus other stabilizing controllers.

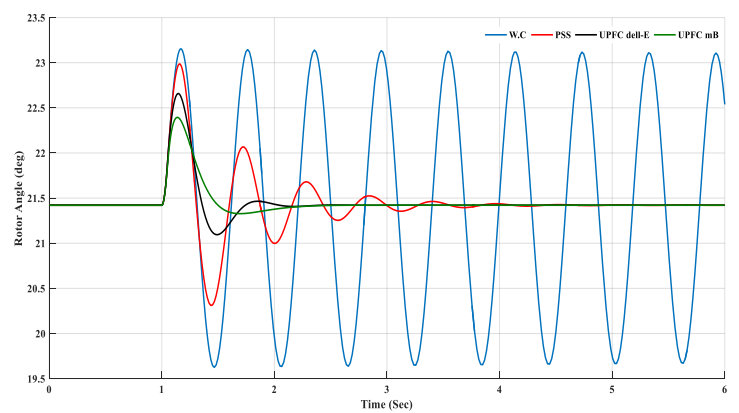

Figure 15: Rotor angle at light load based $f_{l}$.

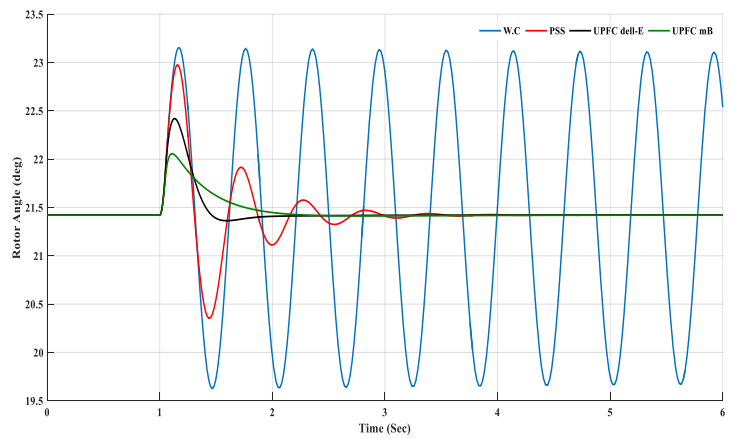

Figure 16: Rotor angle at light load based $f_{2}$.

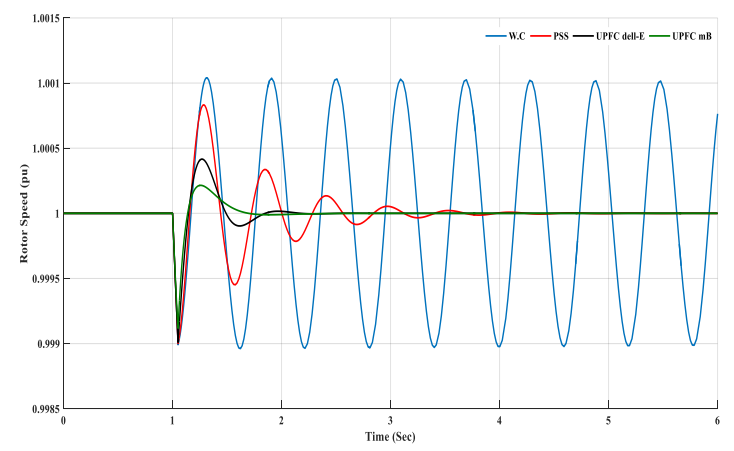

Figure 17: Rotor speed at light load based $f_{l}$.

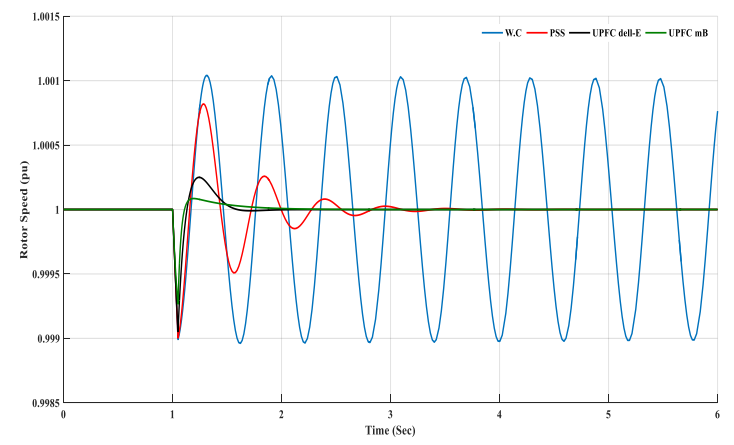

Figure 18: Rotor speed at light load based $f_{2}$. 


\section{CONCLUSION}

In this paper, the mathematical model of UPFC based stabilizing controllers has been investigated. The controllability concept has been employed to define the candidate signals for stabilizing controllers. Eigenvalue based and time-domain based were the objective functions used to get on the optimal tuning settings of stabilizing controllers. PSO algorithm has been utilized to search for optimal settings of parameters of damping controllers. Eigenvalue analysis and time-domain simulation have been adopted when the system subjected to fault under different conditions, to test the effectiveness and robustness of the proposed design approach.

\section{REFERNCE}

[1] Prabha Kundur, "Power system stability and control”, 1 st ed, McGraw-Hill, Inc., 1994.

[2] Narian.G.Hingorani, Laszlo.Gyugyi," Understanding Facts", $1^{\text {st }}$ ed, Wiley Interscience, 2000.

[3] K.R.Padiyar," FACTS controllers in power transmission and distribution”, 1 st ed,New Age International Limited, 2007.

[4] M.A.Abido, A.T.Al-awami, Y.L.Abdel-Magid," Analysis and design of UPFC damping stabilizers for power system stability enhancement", IEEE ISIE 2006, July 9-12, Canada.

[5] Haifeng Wang, Wenjuan Du, “Analysis and damping control of power system low-frequency oscillations”, springer 2016, ISSN: 2196-3185.

[6]A.K. Baliarsingh, D.P.Dash, K.C.Meher, “ A new article of UPFC design for low frequency oscillations using heuristic algorithm”, International journal of modern engineering research (IJMER), vol.2, issue.1,pp-099-109,ISSN:2249-6645.

[7] Randy L.Haupt, Sue Ellen Haupt," Particle genetic algorithm", $2^{\text {nd }}$ ed, Wiley interscience, 2004.

\section{APPENDIX}

SMIB Power System Parameters are:

Machine: $\mathrm{x}_{\mathrm{d}}=1.0, \mathrm{x}_{\mathrm{q}}=0.6, \mathrm{x}_{\mathrm{d}}{ }^{\prime}=0.3, \mathrm{H}=4.0 \mathrm{~s}, \mathrm{f}=50 \mathrm{~Hz}, \mathrm{~T}^{\prime}{ }_{\mathrm{do}}=5.044 \mathrm{~s}, \mathrm{~V}_{\mathrm{t}}=1.0, \mathrm{E}_{\mathrm{b}}=1.0, \mathrm{P}_{\mathrm{e}}=0.9, \mathrm{Q}_{\mathrm{e}}=0.1958$.

Transmission line: $\mathrm{x}_{\mathrm{bv}}=0.6, \mathrm{R}_{\mathrm{e}}=0.0$.

Transformer: $\mathrm{x}_{\mathrm{tr}}=0.1$

UPFC: $\mathrm{x}_{\mathrm{E}}=0.1, \mathrm{x}_{\mathrm{B}}=0.1, \mathrm{C}_{\mathrm{dc}}=3.0, \mathrm{~V}_{\mathrm{dc}}=2.0, \mathrm{~K}_{\mathrm{e}}=3 / 4, \mathrm{~K}_{\mathrm{b}}=3 / 4, \mathrm{~K}_{\mathrm{dp}}=-10 ; \mathrm{K}_{\mathrm{di}}=0.0$;

Exciter: $\mathrm{K}_{\mathrm{A}}=10, \mathrm{~T}_{\mathrm{A}}=0.05 \mathrm{~s}, \mathrm{~T}_{\mathrm{W}}=5.0 \mathrm{~s}$.

\section{BIOGRAPHIS}

Mohammed Osman Hassan: He received his Bachelor degree in Electrical Engineering, and his Master degree in Power System, in 1997, 2003 from Sudan University of Science and Technology (SUST) -Sudan, and his Ph.D., in 2010, from Huazhong University of science and technology (HUST) - China. Currently, he is an Assistant Professor in Sudan University of Science and Technology and a head of nuclear engineering department. He won the prize of best paper in electrical track in ICCCEEE 2018 that held in Sudan. His main research interests are power system control, economic operation of power system, power system stability analysis, FACTS devices and application of AI in power systems.

Ahmed Khaled Alhaj: Received the B.Sc. and M.Sc. degree in Electrical Engineering from Sudan University of Science and Technology-Sudan in 2010 and 2013. Currently he is the Ph.D. student in Electrical and Electronics Engineering at Khartoum University-Sudan. He won the prize of best paper in electrical track in ICCCEEE 2018 that held in Sudan. His areas of interest in research are Power System Dynamics and FACTS Optimization and Artificial Intelligent Application. 